\title{
Pemilihan Dan Pemanfaatan Media Sosial Instagram Sebagai Komunikasi Pemasaran Ascenta Tour
}

\author{
Gabriela Medeline, Eko Harry Susanto \\ Gabriela.915150058@stu.untar.ac.id,ekos@fikom.untar.ac.id
}

Fakultas Ilmu Komunikasi Universitas Tarumanagara

\begin{abstract}
The tourism industry is one of the largest industries in the world, including in Indonesia. By being considered as an industry, this has made tourism a matter of great importance, so it becomes an opportunity for larger companies to entered the tourism business. This can be seen from the number of tourist companies which gave rise to quite high competition. Underlying this, tourism must thoroughly planned the selection of media, efforts and certain ways to attract consumers. This study will discuss the selection of social media, the variety of types of content selected then the social promotion smedia used by the Ascenta Tour. The method used by the researcher is descriptive qualitative method by collecting data from interviews, non-participant observation, documentation and tracking of online data to other references as supporters. The results of this study are Ascenta Tour choosing Instagram social media which is considered as an effective medium, making types of categories made more diverse, advertising promotion with paid usage.
\end{abstract}

Keywords: Instagram, Category content, Paid Promote

\begin{abstract}
Abstrak
Industri pariwisata merupakan salah satu industri terbesar di dunia, termasuk Indonesia. Sehingga dikatakan bahwa industri ini memiliki pengaruh yang cukup besar, sehingga menjadi peluang untuk sebuah bisnis. Banyaknya sosial media yang ada membuat tim pemasar harus memilih media mana yang mampu menjangkau konsumen secara tepat dan luas. Mendasari hal tersebut pemasar harus bersiap penuh dengan pemilihan media, upaya dan cara tertentu untuk menarik konsumen. Penelitian ini akan membahas mengenai pemilihan media sosial, ragam jenis konten yang dipilih lalu promosi media sosial yang digunakan oleh Ascenta Tour. Metode yang digunakan peneliti adalah metode kualitatif deskriptif dengan pengumpulan data dari wawancara, observasi non-partisipan, dokumentasi dan penelusuran data online hingga refrensi lainnya sebagai pendukung. Hasil dari penelitian ini adalah Ascenta Tour memilih sosial media Instagram yang dianggap sebagai media yang efektif, pembuatan jenis kategori konten dibuat beragam sehingga akan lebih menarik, promosi iklan dengan penggunaan paid promote.
\end{abstract}

Kata Kunci : Instagram, Jenis kategori konten, Paid Promote

\section{Pendahuluan}

Pariwisata merupakan salah satu bidang yang mempunyai pengaruh yang besar, bahkan pariwisata sudah menjadi bagian dari kebutuhan dan gaya hidup bagi golongan tertentu. Sebagai peluangnya hal dimanfaatkan banyak pengusaha atau entrepreneur untuk membuka bisnis biro perjalanan wisata atau travel tur. Saat ini sudah banyak sekali perusahaan biro perjalanan wisata, khususnya di Jakarta. Dari perusahaan kecil sampai dengan perusahaan besar biro perjalanan sudah meranah di banyak tempat, Setiap biro perjalanan wisata akan menawarkan beragam jenis 
penawaran menarik dari destinasi domestik hingga destinasi internasional dengan keunggulannya masing-masing.

Untuk itu perusahaan biro perjalanan wisata harus terus selalu berinovasi dan kreatif untuk menarik perhatian konsumen.Untuk itu dimulai dari komunikasi dengan konsumennya, bagaimana komunikasi yang baik dengan konsumen yang sifatnya luas? Sebagai teknologi yang telah berkembang pesat, pemasar harus menggunakan media sebagai perantara antar penjual dan pembeli, media tersebut harus mampu menjangkau target konsumen secara luas khususnya pada yang dijadikan target konsumen dan mampu sebagai jembatan komunikasi.

Ascenta Tour merupakan perusahaan biro perjalanan wisata yang berdiri sejak tahun 2013, memiliki konsep trip terbuka dan trip personal tanpa batasan waktu, kuota dan destinasi, dalam penelitian ini penulis akan mengulas mengenai "Bagaimana pemilihan dan pemanfaatan aplikasi instagram sebagai media komunikasi pemasaran biro perjalanan wisata di Ascenta Tour"

Tujuannya untuk mengetahui banyaknya media sosial yang berpotensi sebagai media promosi , serta upaya dan cara yang dilakukan untuk menarik pelanggan, dan promosi yang digunakan. Penulis akan lebih mendalami mengenai sosial media Instagram dan Ascenta Tour. Sebagai awalnya penulis telah mengetahui bahwa Ascenta Tour menggunakan pemasaran berbasis sosial media Instagram sebagai komunikasi pemasaran utama .Dan diketahui juga bahwa aplikasi instagram mempunyai kekuatan untuk membantu persoalan bisnis, sejalan dengan hal ini Feri Sulianta (2015) bahwa aplikasi instagram merupakan salah satu aplikasi yang tren saat ini.

Sejalan dengan semua itu, penulis berharap dengan adanya penelitian ini mampu memberikan manfaat praktis dan akademis sehingga berguna untuk penelitian berikutnya yang mengulas mengenai sosial media instagram, ataupun komunikasi pemasaran.

Dalam melakukan penelitian ini, penulis menggunakan beberapa teori untuk melengkapi hasil penelitian penulis,

A. Teknologi Komunikasi

Menurut Tubss \& Moss (dalam Susanto, 2009) Agar manusia dapat melakukan proses komunikasi yang baik dan cepat dibutuhkan suatu wadah yaitu teknologi komunikasi.

B. Media Baru

Flew mengatakan (dalam Susanto 2018) media sosial membantu penggunanya untuk berbagi pesan melalui jaringan virtual.

C. Media Sosial

Mayfield menyatakan (dalam Susanto 2018) dengan adanya media sosial akan memudahkan pemakainya untuk membagikan pesan melalui perantara jaringan sosial, media vitual dan lain-lain.

D. Instagram

Sosial media Instagram adalah jejaring sosial media yang dapat diunggah secara gratis pada di android atau ios, fungsinya untuk membagikan gambar dan video. (Jubilee Enterprise 2012)

E. Komunikasi Pemasaran

Menurut Tjiptono (dalam Rahma 2013) kegiatan komunikasi pemasaran adalah kegiatan untuk terus berupaya memberikan informasi serta membujuk publik sehingga konsumen melakukan kegiatan pembelian.

F. Iklan 
Merupakan salah satu kegiatan yang komunikasi pemasaran. Iklan merupakan pesan yang dibuat dengan adanya perencanaan dan dibagikan kepada sekelompok untuk menarik konsumen. (Susanto, 2014)

G. Komunikasi Pariwisata

Menurut Wall dan Mathieson (dalam Rai, 2012) Pariwisata merupakan sebuah aktivitas manusia yang memiliki perencanaan untuk berpergian ke tempat atau daerah, dan tinggal dalam jangka waktu tertentu.

\section{Metode Penelitian}

Sebagai metode penelitian, penulis menggunakan beberapa cara, dalam hal ini penulis menggunakan pendekatan penelitian kualitatif. Sebagai penjelasanya penelitian kualitatif deskriptif, dimana penelitian ini menggunakan tidak menggunakan alat hitung apapun ataupun data statistik melainkan dengan kata-kata, record, atau gambar sebagai pendukung penelitian (Sugiarto 2015)

Sedangkan model yang penulis gunakan adalah studi kasus, model ini menganalisa mengenai suatu kelompok, masyarakat maupun organisasi. Dengan teknik tertentu seperti wawancara, observasi dan dokumentasi. (Sujarweni 2014) Sejalan dengan hal tersebut, penulis menggunakan pengumpulan data dengan teknik wawancara mendalam, observasi non-partisipan, dokumentasi dan penelusuran data online.

Setelah mengetahui judul penelitian penulis, penulis menemukan bahwa subyek penelitian penulis adalah Ascenta Tour dimana pada subyek ini penulis melakukan metode wawancara ke informan kunci dan informan pendukung, sedangkan Objeknya adalah aplikasi Instagram sebagai media komunikasi pemasaran. Sebagai subyeknya, penulis mewawancarai informan pendukung dengan beberapa kriteria tertentu, yaitu memiliki pendidikan terakhir SMA, diyakini dengan pendidikan tersebut dapat memberikan jawaban pertanyaan dengan baik, dan sudah memiliki pengetahuan sedikit mengenai travel. Sebagai kriteria kedua informan pendukung memiliki umur diatas 20 tahun, pada batas usia tersebut sudah memahami aplikasi instagram. Merupakan pengguna aktif instagram, diyakini jika sering memakai aplikasi instagram maka akan memberikan pendapat atau saran kepada penulis yang lebih kritis. Berdomisili di Jakarta, diyakini dengan batas wilayah tersebut penulis dapat mudah menjangkau narasumber, alasan kedua ialah pada insight akun instagram @ ascentatour penikmat-nya sebagian besar ada pada wilayah Jakarta. Memiliki hobi travelling, sesuai dengan judul penelitian penulis yang menyangkut tour travel sehingga topik yang dibahas lebih mengarah pada topik travel.

Tidak hanya itu, penulis menggunakan teknik analisis data, menurut Miles dan Huberman (dalam Susanto, 2018) analisis data untuk menganalisis data yang didapatkan dengan proses yang cukup panjang,

A. Reduksi data, dalam proses pertama ini, data yang dikumpulkan akan dipisahkan sesuai dengan kategori dan kebutuhannya.

B. Informasi dan data yang dikumpulkan akan menghasilkan adanya hipotesis atau kesimpulan.

C. sebagai analisis terakahir, penulis akan mengkaji lagi dengan datadata yang baru dengan metode pengumpulan data dengan mencatat, memperhatikan pola yang terjadi, dan menganalisis sebab akibatnya. 
Sebagai keabsahan suatu data yang diperoleh, penulis menggunakan teknik triagulasi, gunanya untuk mengoreksi data-data yang diperoleh selama penelitian (Gunawan 2014) Dan menurut Moleong (dalam Susanto 2018) Selain menggunakan triagulasi penulis juga disarankan untuk menggunakan analisis data yang lain agar sesuai dengan harapan.

a. Derajat kepercayaan (creadibility) dalam hal ini penulis harus yakin bahwa penelitian akan tercapai dengan baik, hal ini didasari dengan metode-metode yang sudah dilalui wawancara, observasi dan lain-lain.

b. Keteralihan (transferability) mengulas mengenai adanya pengalaman

c. Kebergantungan (dependability) penelitian harus didasari adanya adanya pengukuran.

d. Kepastian (confirmability) menyeleksi data-data yang dipercaya.

\section{Hasil Temuan dan Pembahasan}

Dalam melakukan komunikasi pemasaran, sangat penting melakukan adanya komunikasi dengan konsumen, untuk berkomunikasi dengan konsumen perlu adanya media sebagai perantara, setelah disadari sosial media khususnya sosial media instagram tidak hanya sebagai perantara namun juga berguna sebagai tempat konten dan promosi.

\section{Instagram dijadikan pilihan untuk pemasaran}

Perusahaan biro perjalanan sudah meranah ke banyak tempat, khususnya di Jakarta. ada banyak sekali biro perjalanan dari perusahaan kecil sampai dengan perusahaan besar, bahkan sampai yang tidak berbadan hukum. Setiap perusahaan menawarkan berbagai macam penawaran destinasi dari domestik sampai dengan internasional. Salah satu biro perjalanan yang akan penulis teliti adalah Ascenta Tour. Banyaknya sosial media yang terjadi saat ini membuat pemasar harus memilih media yang tepat untuk menjangkau konsumen.Saat ini sosial media yang ada pada saat ini adalah seperti Facebook, Flickr, Foursquare, Goodreads, Google+, Hi5, Instagram, Kaskus dan lain-lain. Ascenta Tour membutuhkan media yang cocok untuk bisnis, mampu menarik perhatian konsumen, dapat digunakan sebagai perantara komunikasi.Dalam hal ini pemasaran dilakukan berbasis sosial media. Sosial media lahir berdasarkan adanya perkembangan teknologi komunikasi dan era baru yang disebut Internet of Things (IOT). IOT sendiri merupakan realita yang terjadi saat ini, bahwa internet memiliki kemampuan untuk menyelesaikan persoalan manusia.

Sebagai awalnya, Ascenta Tour menggunakan platform Kaskus, dan Facebook akan tetapi kedua platform tersebut tidak menjangkau market yang banyak, hal ini mempengaruhi tim Ascenta Tour untuk berpindah ke media sosial lain yaitu, Instagram. Aplikasi instagram adalah merupakan aplikasi yang dapat diunggah secara gratis, mampu membagikan foto atau video kepada publik dan memiliki pengguna yang berjumlah jutaan orang. (Jubilee Enterprise 2012) Dinilai bahwa instagram mampu menarik konsumen secara luas dan mampu membuat konsumen berpotensi melakukan pembelian.

Sejalan dengan hal tersebut, aplikasi instagram dianggap sebagai salah satu media populer yang dijadikan media komunikasi pemasaran untuk mendapatkan konsumen (Sulianta 2015: 117). Namun masih ditemukan adanya kelemahan dalam melakukan pemasaran berbasis sosial media ini yaitu rendahnya kepercayaan 
konsumen terhadap biro perjalanan, karena tidak ada proses tatap muka secara langsung.

\section{Ragam Jenis Konten akun @ascentatour}

Konten merupakan hal penting bagi sebuah akun sosial media perusahaan, bahkan sebagai gambaran jelas suatu perusahaan. Konten adalah merupakan sebuah iklan yang disebar melalui gambar foto, artikel, dan sebagainya (Sulianta 2015:18) Ascenta Tour memiliki beberapa ragam jenis konten di dalam akun @ascentatour yaitu, paket tour, meme, testimoni, infografis, informasi tempat, re-post, quotes, tanya jawab, promo, dan giveaway. Diakui bahwa pemilihan konten ini memang berbeda dengan akun-akun travel lainnya yang menekankan pada hard selling. Menurut tim media sosial Ascenta Tour alasan pemilihan konten ini adalah karena Ascenta Tour ingin membuat konten yang tidak hanya memberikan informasi namun juga hiburan dan edukasi.

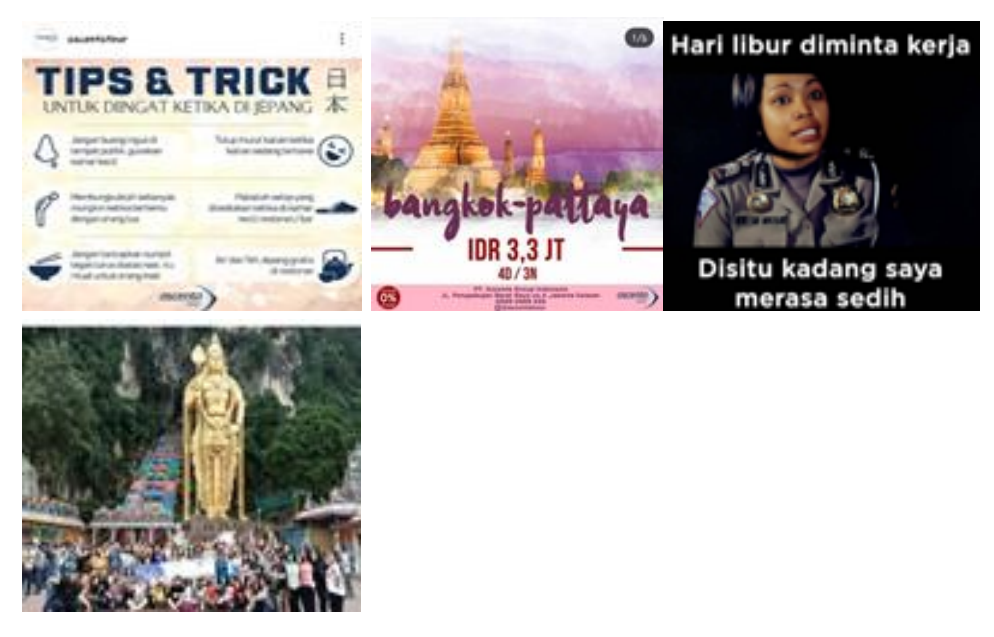

Gambar1.: Konten akun @ascentatour Sumber : Dokumentasi Pribadi

Pemilihan konten tersebut dibuat untuk konsumen/pengikut atau followers akun@ascentatour. Untuk itu penulis sudah melakukan wawancara kepada lima narasumber untuk mendapatkan jawaban mengenai konten yang ada pada akun @ascentatour. Kelima narasumber memberikan jawaban yang baik dan jelas. Sebagai persamaannya narasumber menilai bahwa mereka menyukai konten yang dibuat Ascenta Tour, untuk kedepannya ragam jenis kategori harus lebih divariasikan lagi. Jenis kategori konten yang disukai adalah paket tour, meme, dan infografis. Sejalan dengan hal tersebut narasumber memberikan saran-saran penunjang contohnya perlunya peningkatan lebih baik lagi untuk pemilihan konten.

\section{Promosi Paid Promote}

Berbicara mengenai promosi secara tidak langsung membicarakan sebuah iklan. Promosi merupakan bagian dari komunikasi pemasaran, sebagai iklan promosi yang menarik adalah promosi yang lebih menekankan dan menjangkau target, Ascenta Tour menggunakan cara dengan promosi berbayar yang disebut paid promote di Instagram . Promosi Paid Promote merupakan promosi berbayar yang ada di aplikasi instagram. Menurut Arif (2016) akun paid promote dapat digunakan untuk mempromosikan akun bisnis. Ascenta Tour menggunakan beberapa akun paid 
promote tertentu untuk mempromosikan bisnisnya, akun yang dipilih hingga saat ini adalah akun@lambe_turah, @katalogpromosi dan@promotrip. Alasan pemilihan akun ini ialah berbeda-beda akan tetapi kesamaannya adalah memiliki followers yang banyak dan insight yang sama dengan akun @ascentatour. Insight dapat dilihat dengan adanya kesamaan demografi lokasi, umur dan jenis kelamin. Hal ini dilakukan agar promosi yang dikeluarkan terarah dengan target yang dimiliki oleh akun bisnis.

Sebagai hasilnya akun @lambe_turah dinilai paling efektif dalam melakukan promosi, terlihat pada hasil likes, komentar, dan pengikut yang berkunjung pada profil akun@ascentatour. Hal ini terlihat pada hasil yang iklan pada

\section{Kesimpulan}

Pada kesimpulan ini, penulis akan menyimpulkan hasil dari penelitian yang telah penulis rangkum,

A. Dengan banyaknya media yag ada saat ini, seperti Facebook, Flickr, Foursquare, Goodreads, Google+, Hi5, Instagram, Kaskus dan lain-lain. Ascenta Tour harus memilih media yang cocok untuk menjangkau konsumennya. Yaitu media yang cocok untuk bisnis, media yang mampu menjangkau konsumen, melakukan promosi, dan penyebaran konten. Sampai dengan detik ini pemilihan media Instagram merupakan pilihan paling tepat bagi pemasaran Ascenta Tour.

B. Upaya yang dilakukan untuk menarik pengikut atau konsumen adalah menggunakan jenis kategori konten, terdapat sepuluh jenis kategori konten yang digunakan akun @ascentatour, yaitu paket tour, meme, testimoni, infografis, informasi tempat, re-post, quotes, tanya jawab, promo dan giveaway. Setelah melakukan wawancara penulis menemukan bahwa konten yang paling diminati oleh pengikut atau konsumen adalah paket tour, infografis dan meme.

C. Sebagai bentuk promosi yang lebih menjangkau target, Ascenta Tour menggunakan Paid Promote atau promosi berbayar, akun promosi berbayar yang dipilih Ascenta Tour adalah @lambe_turah.

\section{Ucapan Terima Kasih}

Penulis mempersembahkan penelitian ini untuk segenap keluarga, sahabat, dan teman. Terutama kepada Bapak Dr. Eko Harry Susanto M.Si selaku dosen pembimbing yang memberikan bimbingan arahan dan bimbingan dengan baik kepada penulis selama bimbingan berlangsung. Tidak lupa penulis juga mengucapkan terima kasih kepada segenap tim Ascenta Tour yang senantiasa membantu proses pembuatan skripsi ini hingga berjalan dengan baik.

\section{Daftar Pustaka}

Enterprise, Jubilee. 2012. Instagram untuk Fotografi Digital dan Bisnis $\quad$ Kreatif. Jakarta:PT Elex Media Komputindo

Gunawan, Imam. 2014. Metode Penelitian Kualitatif Teori \& Praktik. Jakarta: Bumi Aksara 
Gabriela Medeline, Eko Harry Susanto: Pemilihan Dan Pemanfaatan Media Sosial Instagram Sebagai

Rai, I Gusti. 2014. Pengantar Industri Pariwisata. Yogyakarta: CV Budi Utama Rohmadi, Arif.2016. Tips Produktif Ber-Social Media. Jakarta:

PT Elex Media Komputindo

Rohmadi, Arif.2016. Tips Produktif Ber-Social Media.Jakarta: PT Elex Media Komputindo

Sugiarto, Eko.2015.Menyusun Proposal Penelitian Kualitatif Skripsi dan Tesis. Yogyakarta: Suaka Media

Sujarweni, Wiratna. 2014. Metodologi Penelitian Lengkap, Praktis, dan Mudah Dipahami.Yogyakarta: Pustaka Baru Press

Sulianta, Feri. 2015. Keajaiban Sosial Media. Jakarta: PT. Elex Media Komputindo

Susanto, Eko Harry .2009. Komunikasi Politik Dan Otonomi Daerah: Tinjau

Terhadap Dinamika Politik dan Pembangunan. Jakarta: Penerbit

Mitra Wacana Media

Susanto, Eko Harry.2014.Dinamika Pesan Iklan.Jurnal Komunikasi Universitas

Tarumanagara

Susanto, Eko Harry.2018. Komunikasi Manusia: Teori dan Praktik Dalam

Penyampaian Gagasan. Jakarta: Penerbit Mitra Wacana Media

Zinaida, Rahma. 2013. Marketing Communication Pariwisata dan Korporasi di Indonesia. Jakarta: Penerbit Studi Komunikasi dan Bisnis Program Pasca Sarjana Universitas Mercu Buana 